\title{
The cytoskeleton and the cellular transduction of mechanical strain in the heart: a special issue
}

\author{
Pieter P. de Tombe $\cdot$ Henk L. Granzier
}

Received: 11 April 2011 /Revised: 5 May 2011 / Accepted: 6 May 2011/Published online: 19 May 2011

(C) Springer-Verlag 2011

There is a fundamental requirement for all cells to communicate and process information with regard to their surroundings and this is accomplished by vast array of signals that, at its basis, are all based on four principal physical processes: electricity, force, chemical reaction, and light. Mechanical strain sensing in muscle is unique in that forces are both generated by the muscle cells itself ("insideout" pathway) as well as acted upon these cells from the exterior ("outside-in" pathway). These mechanisms are critically important in the heart to alter its form and function and meet varied hemodynamic demands. Accordingly, this special issue of Pflüger's Archiv European Journal of Physiology is focused on the cellular transduction of mechanical strain in the heart. The issue is composed of invited reviews written by world leaders in their respective fields of research.

A well-known example of acute strain regulation in cardiac tissue is the Frank-Starling Law of the heart [9]. Interestingly, although this basic beat-to-beat regulatory mechanism has been appreciated for over a century, the cellular mechanisms that underlie this strain transduction system have only been identified in recent decades as being caused by (a) an immediate change in cardiac cell

\section{P. P. de Tombe ( $\triangle)$}

Department of Cell and Molecular Physiology,

Loyola University Chicago, Stritch School of Medicine,

2160 South First Ave,

Maywood, IL 60153-5500, USA

e-mail: pdetombe@lumc.edu

\section{H. L. Granzier}

Molecular Cardiovascular Research Program,

University of Arizona,

Medical Research Building, room 325, 1656 East Mabel Street,

Tucson, AZ 85724-5217, USA

e-mail: granzier@email.arizona.edu contractility that is secondary to changes in contractile protein $\mathrm{Ca}^{2+}$ sensitivity $[11,12]$, and (b) a slower change in cardiac cell contractility that develops over the course of several beats that is secondary to changes in intracellular $\mathrm{Ca}^{2+}$ homeostasis $[1,17]$. However, the molecular mechanisms and cellular signal transduction processes that underlie these cellular regulatory systems are still under intense investigation [9]. In this issue, this area of research is reviewed by contributions from the groups of Campbell [5], Cazorla [6], Cingolani [7], Peter Kohl [2], Landesberg [23], and McDonald [16].

Cardiac muscle cells are dynamic; increased mechanical load induces a hypertrophic response, while reduced load elicits the reverse response [21]. The cellular signal transduction processes responsible for this tight, long term, regulatory system that leads to remodeling of the sarcomeric architecture in the cardiac muscle cell are varied and complex. In addition, the cardiac cell is integrated into the extracellular scaffolding and force transmission system formed by the extracellular matrix, which itself is a dynamic structure that is subject to regulation and remodeling. This rapidly expanding area of research is reviewed in this special issue by contributions from the groups of Borg [3], Kresh [13], Parker [15], and Russell [8].

Among the several cytoskeletal protein structures that play a role in the cellular transduction system, the giant sarcomeric protein titin (the "fourth filament") is particularly intriguing. Titin's role as the predominant contributor to passive force generation within the physiological range in striated muscle is now well established [14]. However, recent observations indicate a far greater role of this giant protein in a vast array of cellular functions, including the response to cellular strain in myofilament length dependent activation, protein turnover, hypertrophic responses, and modulation of cardiac function in cardiac pathologies such 
as diastolic heart failure. This area of research is reviewed by contributions from the groups of Gautel [10], Knoll [4], Linke [20], and van der Velden [19].

Finally, electrical activity of cardiac cells is also a critical functional component of the heart. Recent data have revealed that ionic currents traversing the cell membrane in cardiac cells are not only regulated by hormone based regulatory system but also directly via a mechanic strain transduction system. Electromechanical coupling of cardiac cells is reviewed in this issue in the context of the contractile protein system by the group of ter Keurs [18] and the microtubular system by the group of White [22].

In summary, the regulation of cardiac function by mechanical strain is a rapidly expanding field that touches on a wide array of disciplines, ranging from cell biology, biophysics, signal transduction, to molecular biology. With that in mind, Henk and I have asked the contributors to provide us not only with critical in-depth reviews of their respective fields, but also overviews that include personal opinions and global perspectives. We believe the contributors have succeeded in that goal and it is, therefore, only fitting that these invited reviews are compiled and published together in a journal of physiology, a fundamentally integrative discipline.

Funding Research in our laboratories is supported by grants from the National Institutes of Health [HL RO1 75494 and HL PO1 62426 (to P. deT.) and HL 062881 (to HG), and from the American Heart Association.

\section{References}

1. Allen DG, Kurihara S (1982) The effects of muscle length on intracellular calcium transients in mammalian cardiac muscle. J Physiol 327:79-94

2. Bollensdorff C, Lookin O, Kohl P (2011) Assessment of contractility in intact ventricular cardiomyocytes using the dimensionless 'Frank-Starling Gain' index. Pflugers Arch. 462:39-48

3. Borg TK, Baudino TA (2011) Dynamic interactions between the cellular components of the heart and the extracellular matrix. Pflugers Arch. 462:69-74
4. Buyandelger B, Ng KE, Miocic S, Piotrowska I, Gunkel S, Ku $\mathrm{CH}$, Knoll R (2011) MLP (muscle LIM protein) as a stress sensor in the heart. Pflugers Arch. 462:135-142

5. Campbell KS (2011) Impact of myocyte strain on cardiac myofilament activation. Pflugers Arch. 462:3-14

6. Cazorla O, Lacampagne A (2011) Regional variation in myofilament length-dependent activation. Pflugers Arch 462:15-28

7. Cingolani HE, Ennis IL, Aiello EA, Perez NG (2011) Role of autocrine/paracrine mechanisms in response to myocardial strain. Pflugers Arch. 462:29-38

8. Curtis MW, Russell B (2011) Micromechanical regulation in cardiac myocytes and fibroblasts: implications for tissue remodeling. Pflugers Arch. 462:105-117

9. de Tombe PP, Mateja RD, Tachampa K, Mou YA, Farman GP, Irving TC (2010) Myofilament length dependent activation. J Mol Cell Cardiol 48:851-858

10. Gautel M (2011) Cytoskeletal protein kinases: titin and its relations in mechanosensing. Pflugers Arch. 462:119-134

11. Hibberd MG, Jewell BR (1982) Calcium- and length-dependent force production in rat ventricular muscle. J Physiol 329:527-540

12. Kentish JC, ter Keurs HE, Ricciardi L, Bucx JJ, Noble MI (1986) Comparison between the sarcomere length-force relations of intact and skinned trabeculae from rat right ventricle. Influence of calcium concentrations on these relations. Circ Res 58:755-768

13. Kresh JY, Chopra A (2011) Intercellular and extracellular mechanotransduction in cardiac myocytes. Pflugers Arch. 462:75-87

14. LeWinter MM, Granzier H (2010) Cardiac titin: a multifunctional giant. Circulation 121:2137-2145

15. McCain ML, Parker KK (2011) Mechanotransduction: the role of mechanical stress, myocyte shape, and cytoskeletal architecture on cardiac function. Pflugers Arch. 462:89-104

16. McDonald KS (2011) The interdependence of $\mathrm{Ca}(2+)$ activation, sarcomere length, and power output in the heart. Pflugers Arch. 462:61-67

17. Parmley WW, Chuck L (1973) Length-dependent changes in myocardial contractile state. Am J Physiol 224:1195-1199

18. Ter Keurs HE (2011) Electromechanical coupling in the cardiac myocyte; stretch-arrhythmia feedback. Pflugers Arch. 462:165-175

19. van der Velden J (2011) Diastolic myofilament dysfunction in the failing human heart. Pflugers Arch. 462:155-163

20. Voelkel T, Linke WA (2011) Conformation-regulated mechanosensory control via titin domains in cardiac muscle. Pflugers Arch. 462:143-154

21. Wang Y (2007) Mitogen-activated protein kinases in heart development and diseases. Circulation 116:1413-1423

22. White E (2011) Mechanical modulation of cardiac microtubules. Pflugers Arch. 462:177-184

23. Yadid M, Sela G, Amiad Pavlov D, Landesberg A (2011) Adaptive control of cardiac contraction to changes in loading: from theory of sarcomere dynamics to whole-heart function Pflugers Arch. 462:49-60 